Cite as:

A. Karton, R. J. O’Reilly, L. Radom, J. Phys. Chem. A 116, 4211-4221 (2012).

\title{
Assessment of Theoretical Procedures for Calculating Barrier Heights for a Diverse Set of Water-Catalyzed Proton-Transfer Reactions
}

\author{
Amir Karton,* Robert J. O'Reilly and Leo Radom* \\ School of Chemistry and ARC Centre of Excellence for Free Radical Chemistry and \\ Biotechnology, University of Sydney, Sydney, NSW 2006, Australia
}

ABSTRACT: Accurate electronic barrier heights are obtained for a set of nine protontransfer tautomerization reactions, which are either: (i) uncatalyzed, (ii) catalyzed by one water molecule, or (iii) catalyzed by two water molecules. The barrier heights for reactions (i) and (ii) are obtained by means of the high-level ab initio W2.2 thermochemical protocol, while those for reaction (iii) are obtained using the $\mathrm{W} 1$ protocol. These three sets of benchmark barrier heights allow an assessment of the performance of more approximate theoretical procedures for the calculation of barrier heights of uncatalyzed and watercatalyzed reactions. We evaluate initially the performance of the composite G4 procedure and variants thereof (e.g., G4(MP2) and G4(MP2)-6X), as well as that of standard ab initio procedures (e.g., MP2, SCS-MP2, and MP4). We find that the performance of the G4(MP2)type thermochemical procedures deteriorates with the number of water molecules involved in the catalysis. This behavior is linked to deficiencies in the MP2-based basis-set-correction term in the G4(MP2)-type procedures. This is remedied in the MP4-based G4 procedure, which shows good performance for both the uncatalyzed and water-catalyzed reactions, with mean absolute deviations (MADs) from the benchmark values lying below the threshold of 'chemical accuracy' (arbitrarily defined as $1 \mathrm{kcal} \mathrm{mol}^{-1} \approx 4.2 \mathrm{~kJ} \mathrm{~mol}^{-1}$ ). We also examine the performance of a large number of density functional theory (DFT) and double-hybrid DFT (DHDFT) procedures. We find that, with few exceptions (most notably PW6-B95 and B972 ), the performance of the DFT procedures that give good results for the uncatalyzed reactions deteriorates with the number of water molecules involved in the catalysis. The DHDFT procedures, on the other hand, show excellent performance for both the uncatalyzed and catalyzed reactions. Specifically, almost all of them afford MADs below the 'chemical accuracy' threshold, with ROB2-PLYP and B2K-PLYP showing the best overall performance.

Keywords: Tautomerization, barrier heights, water-assisted, DFT, double-hybrid, G4, G4(MP2). 


\section{INTRODUCTION}

Proton-transfer reactions are ubiquitous throughout chemistry and biology. ${ }^{1}$ They play pivotal roles in numerous biochemical processes, for example in enzyme catalysis and in light-induced proton pumps. Prototropic tautomerizations represent a subclass of such processes, and are also the most common form of tautomerism, ${ }^{2}$ with the keto-to-enol and amide-to-imidol equilibria as familiar examples. From a biological perspective, some tautomerization processes have significant biological implications. For example, rare tautomers of the nucleobases can lead to spontaneous mutations in DNA due to their altered base-pairing properties. ${ }^{3}$ Another example is that the high phosphate-transfer potential of phosphoenolpyruvate results from the fact that the phosphorylated compound is trapped in the less stable enol form, and after dephosphorylation it can assume the keto form.

The presence of one (or more) explicit water molecules can dramatically enhance the reaction rates of prototropic tautomerizations relative to the rates of the uncatalyzed reactions. Thus, modeling the reaction kinetics of such processes in an environment that includes water molecules (such as aqueous solution or the active site of an enzyme) requires consideration of explicit water molecules in the theoretical model. Indeed, a steadily growing number of theoretical investigations in the past decade have appeared in the literature that attempt to investigate the role of explicit water molecules in tautomerization reactions, where typically between one to three explicit water molecules are used. Notable examples include the study of the transformation of fructose to hydroxymethyl furfural, ${ }^{4}$ the conversion of ammonium cyanate into urea (Wöhler's reaction), ${ }^{5}$ and the tautomerization processes in molecules such as formamide, ${ }^{6}$ guanine, $^{7}$ cyanuric $^{8}$ and cyameluric ${ }^{9}$ acids, uracil and 5bromouracil, ${ }^{10}$ 2-, 3-, and 4-formylpyridine semicarbazones, ${ }^{11}$ simple peptide models, ${ }^{12}$ pyruvate and acetylacetone, ${ }^{13}$ as well as the tautomeric equilibria and catalytic ylide generation of thiamin models. ${ }^{14,15}$

Motivated by the ever-increasing number of studies being reported for such processes, we introduce in the present work a representative database of high-level barrier heights for a selection of water-catalyzed proton-transfer reactions (to be known as the WCPT set of electronic barrier heights). ${ }^{16}$ The reactions that we have examined (shown in Figure 1) are of the type $\mathrm{X}=\mathrm{CH}-\mathrm{YH} \rightarrow \mathrm{HX}-\mathrm{CH}=\mathrm{Y}$, and include carbonyls $\left(\mathrm{X}=\mathrm{O} ; \mathrm{Y}=\mathrm{O}, \mathrm{NH}\right.$, and $\mathrm{CH}_{2}$, reactions 1-3), imines $\left(\mathrm{X}=\mathrm{NH} ; \mathrm{Y}=\mathrm{NH}\right.$ and $\mathrm{CH}_{2}$, reactions 4-5), propene $\left(\mathrm{X}=\mathrm{CH}_{2} ; \mathrm{Y}=\right.$ $\mathrm{CH}_{2}$, reaction 6), and thiocarbonyls $\left(\mathrm{X}=\mathrm{S} ; \mathrm{Y}=\mathrm{O}, \mathrm{NH}\right.$, and $\mathrm{CH}_{2}$, reactions 7-9). The WCPT dataset includes barrier heights for three sets of reactions: (i) uncatalyzed, (ii) catalyzed by 
one water molecule, and (iii) catalyzed by two water molecules. All the barrier heights are obtained by means of the high-level W2.2 or W1 procedures. The benchmark values allow us to assess the performance of more approximate theoretical procedures for the variety of both uncatalyzed and water-catalyzed reactions. Specifically, we examine the performance of a number of high-level composite thermochemistry procedures, and several conventional ab initio methods, as well as a variety of contemporary density functional theory (DFT) procedures, including the recently developed double-hybrid DFT (DHDFT) methods.

(1)

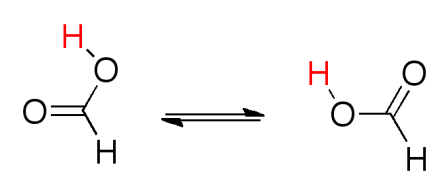

(2)

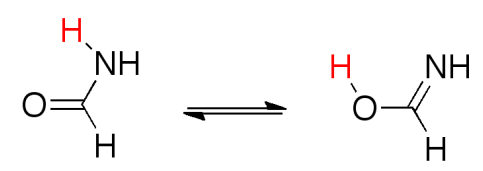

(3)

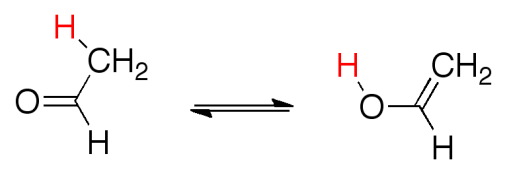

(4)

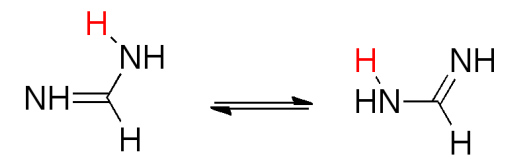

(5)

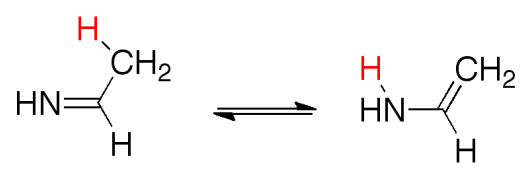

(6)

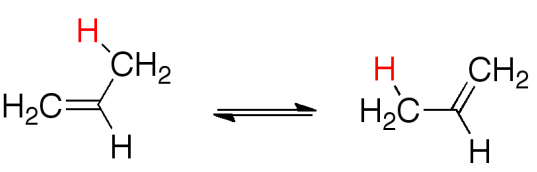

(7)

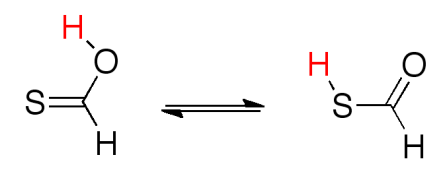

(8)

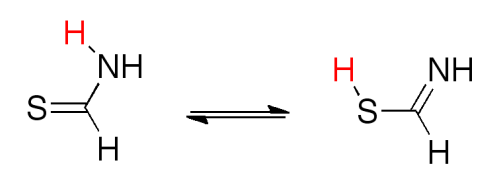

(9)

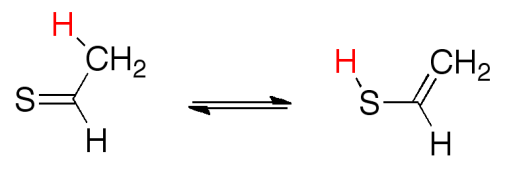

Figure 1. Prototropic tautomerization reactions in the WCPT dataset. The transferred proton is colored in red. 


\section{COMPUTATIONAL PROCEDURES}

The geometries of all structures have been obtained at the B3-LYP/A'VTZ level of theory, where $\mathrm{A}^{\prime} \mathrm{V} n \mathrm{Z}$ indicates the combination of standard correlation-consistent cc-pVnZ basis sets ${ }^{17}$ on $\mathrm{H}$, aug-cc-pVnZ basis sets ${ }^{18}$ on first-row elements, and aug-cc-pV $(n+\mathrm{d}) \mathrm{Z}$ basis sets $^{19}$ on second-row elements. Harmonic vibrational analyses have been performed to confirm each stationary point as either an equilibrium structure (i.e., all real frequencies) or a transition structure (TS) (i.e., with one imaginary frequency). All geometry optimizations and frequency calculations were performed using the Gaussian 09 program suite. ${ }^{20}$

In order to obtain reliable barrier heights, calculations have been carried out using the high-level ab initio W2.2 and/or W1 thermochemical protocols with the Molpro 2010.1 program suite. ${ }^{21} \mathrm{~W} 2.2^{22}$ and $\mathrm{W} 1^{23}$ both represent layered extrapolations to the all-electron $\operatorname{CCSD}(\mathrm{T})$ (coupled cluster with singles, doubles, and quasiperturbative triple excitations) basis-set limit, and can achieve an accuracy in the $\mathrm{kJ} \mathrm{mol}^{-1}$ range for molecules whose wave functions are dominated by dynamical correlation. ${ }^{24}$ For example, for a set of 25 molecules whose wave functions are dominated by dynamical correlation and for which highly accurate experimental atomization energies are available, ${ }^{25} \mathrm{~W} 2.2$ affords a root-mean-square deviation from these energies of just $1.0 \mathrm{~kJ} \mathrm{~mol}^{-1} .^{24}$ This implies a $95 \%$ confidence interval of $\sim 2 \mathrm{~kJ}$ $\mathrm{mol}^{-1}$ for the W2.2 procedure.

The computational protocol of the W2.2 method has been specified and rationalized in detail previously. ${ }^{22}$ In brief, the Hartree-Fock component is extrapolated from the A'VQZ and $A^{\prime} \mathrm{V} 5 \mathrm{Z}$ basis sets. The valence CCSD correlation energy is obtained using the same basis sets, where the singlet-coupled and triplet-coupled pair energies are extrapolated with the $\mathrm{E}(L)=\mathrm{E}_{\infty}+A / L^{\alpha}$ two-point extrapolation formula, with $\alpha=3$ and 5 , respectively, and the singles-excitation term is simply set equal to that in the largest basis set. The $(T)$ valence correlation energy is extrapolated from the $\mathrm{A}^{\prime} \mathrm{VTZ}$ and $\mathrm{A}^{\prime} \mathrm{VQZ}$ basis sets using the above two-point extrapolation formula with $\alpha=3$. The $\operatorname{CCSD}(\mathrm{T})$ inner-shell contribution is extrapolated from the core-valence weighted correlation-consistent aug'-cc-pwCVTZ and aug'-cc-pwCVQZ basis sets of Peterson and Dunning. ${ }^{26}$ The computationally more economical W1 procedure uses smaller basis sets for the HF, CCSD, (T), and inner-shell contributions. Specifically, the HF, CCSD, and (T) contributions are extrapolated from the $\mathrm{A}^{\prime} \mathrm{V}\{\mathrm{T}, \mathrm{Q}\} \mathrm{Z}, \mathrm{A}^{\prime} \mathrm{V}\{\mathrm{T}, \mathrm{Q}\} \mathrm{Z}$, and $\mathrm{A}^{\prime} \mathrm{V}\{\mathrm{D}, \mathrm{T}\} \mathrm{Z}$ basis-set pairs, respectively, using the two-point extrapolation formula with $\alpha=5,3.22$, and 3.22, respectively. The inner-shell contribution is 
obtained at the $\operatorname{CCSD}(\mathrm{T})$ level using the MTsmall basis set (where MTsmall denotes a completely uncontracted cc-pVTZ basis set with additional $2 d 1 f$ high-exponent functions). ${ }^{23}$ Finally, we note that the reaction barriers are obtained on the electronic potential energy surface (i.e., relativistic, zero-point, thermal, entropic, and tunneling contributions are not included).

Since W2.2 and W1 represent layered extrapolations to the all-electron CCSD(T) basis-set-limit energy, it is of interest to estimate whether the contributions from post$\operatorname{CCSD}(\mathrm{T})$ excitations are likely to be significant. The percentage of the atomization energy accounted for by parenthetical connected triple excitations, \% $\mathrm{TAE}_{e}[(\mathrm{~T})]$, has been shown to be a reliable energy-based diagnostic indicating the importance of nondynamical correlation effects. It has been suggested that $\% \mathrm{TAE}_{e}[(\mathrm{~T})]<2 \%$ indicates systems that are dominated by dynamical correlation, while $2 \%<\% \mathrm{TAE}_{e}[(\mathrm{~T})]<5 \%$ indicates systems that include mild non-dynamical correlation. ${ }^{22}$ Table $\mathrm{S} 1$ of the Supporting Information gathers the $\left.\% \mathrm{TAE}_{e}[\mathrm{~T})\right]$ values for the transition structures (TS) considered in the present study. The $\% \mathrm{TAE}_{e}[(\mathrm{~T})]$ values for the uncatalyzed TSs lie in the range $2.2-3.8 \%$. The water-catalyzed TSs are characterized by slightly lower \% $\left.\mathrm{TAE}_{e}[\mathrm{~T})\right]$ values, ranging between $1.9-2.9 \%$. These values suggest that our benchmark barrier heights should, in principle, be within $\pm 1 \mathrm{~kJ} \mathrm{~mol}^{-1}$ of the barrier heights at the full configuration interaction (FCI) basis-set limit. ${ }^{24}$

In Section 3.3, we use our W2.2 and W1 benchmark barrier heights to evaluate the performance of a number of standard ab initio procedures (MP2, SCS-MP2, ${ }^{27}$ and MP4) as well as that of the composite G4 procedure ${ }^{28}$ and variants thereof (G4(MP2) ${ }^{29}$ and G4(MP2)$\left.6 \mathrm{X}^{30}\right)$. For the sake of making the article self-contained, we will briefly outline the various steps in the G4 and G4(MP2) methods (for further details see references 28 and 29).

For reactions that involve only closed-shell species, the electronic G4 energy is given by

$E[\mathrm{G} 4]=E[\mathrm{CCSD}(\mathrm{T}) / 6-31 \mathrm{G}(\mathrm{d})]+\Delta E(+)+\Delta E(2 \mathrm{df}, \mathrm{p})+\Delta E(\mathrm{G} 3 \mathrm{LargeXP})+\Delta E(\mathrm{HF})$

where the basis-set-correction terms are given by

$\Delta E(+)=E[\mathrm{MP} 4 / 6-31+\mathrm{G}(\mathrm{d})]-E[\mathrm{MP} 4 / 6-31 \mathrm{G}(\mathrm{d})]$

$\Delta E(2 \mathrm{df}, \mathrm{p})=E[\mathrm{MP} 4 / 6-31+\mathrm{G}(2 \mathrm{df}, \mathrm{p})]-E[\mathrm{MP} 4 / 6-31 \mathrm{G}(\mathrm{d})]$ 
$\Delta E(\mathrm{G} 3 \mathrm{LargeXP})=E[\mathrm{MP} 2($ full) $/ \mathrm{G} 3 \mathrm{LargeXP}]-E[\mathrm{MP} 2 / 6-31 \mathrm{G}(2 \mathrm{df}, \mathrm{p})]-E[\mathrm{MP} 2 / 6-31+\mathrm{G}(\mathrm{d})]+$ $E[\mathrm{MP} 2 / 6-31 \mathrm{G}(\mathrm{d})]$

$\Delta E(\mathrm{HF})=E[\mathrm{HF} /\{\mathrm{Q}, 5\}]-E[\mathrm{HF} / \mathrm{G} 3 \mathrm{LargeXP}]$

Here, $\mathrm{HF} /\{\mathrm{Q}, 5\}$ indicates extrapolation of the HF energy from truncated versions of the augcc-pVQZ and aug-cc-pV5Z basis sets.

The computationally more economical G4(MP2) method includes only one basis-setcorrection term, calculated at the MP2 level (in addition to the $\Delta E(\mathrm{HF})$ correction term). The G4(MP2) electronic energy is given by

$E[\mathrm{G} 4(\mathrm{MP} 2)]=E[\mathrm{CCSD}(\mathrm{T}) / 6-31 \mathrm{G}(\mathrm{d})]+\Delta E(\mathrm{MP} 2)+\Delta E(\mathrm{HF})$

where the basis-set-correction terms are given by

$$
\begin{aligned}
& \Delta E(\mathrm{MP} 2)=E[\mathrm{MP} 2 / \mathrm{G} 3 \mathrm{MP} 2 \mathrm{LargeXP}]-E[\mathrm{MP} 2 / 6-31 \mathrm{G}(\mathrm{d})] \\
& \Delta E(\mathrm{HF})=E[\mathrm{HF} /\{\mathrm{T}, \mathrm{Q}\}]-E[\mathrm{HF} / \mathrm{G} 3 \mathrm{MP} 2 \mathrm{LargeXP}]
\end{aligned}
$$

Here, $\mathrm{HF} /\{\mathrm{T}, \mathrm{Q}\}$ indicates extrapolation of the HF energy from truncated versions of the augcc-pVTZ and aug-cc-pVQZ basis sets.

In Section 3.3 we will also consider modified versions of the G4(MP2) energy expression

$$
E[\mathrm{G} 4(\mathrm{MP} n)]=E[\mathrm{CCSD}(\mathrm{T}) / 6-31 \mathrm{G}(\mathrm{d})]+\Delta E(\mathrm{MP} n)+\Delta E(\mathrm{HF})
$$

The MP $n$ basis-set-correction term is given by

$$
\Delta E(\mathrm{MP} n)=E[\mathrm{MP} n / \mathrm{G} 3 \mathrm{MP} 2 \mathrm{LargeXP}]-E[\mathrm{MP} n / 6-31 \mathrm{G}(\mathrm{d})]
$$

where MP $n=$ MP3 or MP4.

In Section 3.4, we evaluate the performance of a variety of DFT procedures, including recently developed DHDFT methods. The DFT exchange-correlation functionals considered in the present study (ordered by their rung on Perdew's 'Jacob's Ladder of DFT' ${ }^{\text {,31 }}$ ) are the 
pure generalized gradient approximation (GGA) methods: B-LYP, ${ }^{32,33}$ B-P86, ${ }^{32,34}$ PBE, ${ }^{35}$ HCTH407, ${ }^{36}$ and B97-D; ${ }^{37}$ the meta-GGAs (MGGAs): VSXC, ${ }^{38} \mathrm{TPSS}^{39} \tau-{ }^{39} \mathrm{HCTH}^{40}$ and M06-L; ${ }^{41}$ the hybrid-GGAs: PBE0, ${ }^{42}$ B3-PW91, ${ }^{43,44}$ B3-P86, ${ }^{34,44} \mathrm{~B} 97-1,{ }^{45} \mathrm{~B} 98,{ }^{46} \mathrm{TPSSh},{ }^{47} \mathrm{~B} 3-$ LYP,${ }^{33,44,48}$ X3-LYP,${ }^{49}$ BH\&HLYP $,{ }^{50} \omega \mathrm{B} 97,{ }^{51} \omega \mathrm{B} 97 \mathrm{X},{ }^{51}$ and $\omega \mathrm{B} 97 \mathrm{X}-\mathrm{D} ;{ }^{52}$ the hybrid-metaGGAs (HMGGAs): B1-B95, ${ }^{32,53} \mathrm{BMK},{ }^{54} \tau$-HCTHh, ${ }^{40} \mathrm{M} 05,{ }^{55} \mathrm{M} 05-2 \mathrm{X},{ }^{56} \mathrm{M} 06,{ }^{57} \mathrm{M} 06-2 \mathrm{X},{ }^{57}$ and M06-HF; ${ }^{57}$ and the DHDFT procedures: B2-PLYP,${ }^{58}$ B2T-PLYP,${ }^{59}$ B2K-PLYP,${ }^{59}$ B2GPPLYP ${ }^{60}$ ROB2-PLYP,${ }^{61}$ and DSD-BLYP. ${ }^{62}$

To ensure that the performance of the various DFT procedures is evaluated on an equal footing and that errors arising from basis-set incompleteness are not significant, the DFT and DHDFT calculations are carried out with large basis sets. In particular, the conventional DFT calculations (rungs 1-4 of Jacob's Ladder) are carried out with the aug'pc-3 $+\mathrm{d}$ basis set ${ }^{63}$ (which is of $5 \mathrm{~s} 4 \mathrm{p} 2 \mathrm{~d} 1 \mathrm{f}, 7 \mathrm{~s} 6 \mathrm{p} 5 \mathrm{~d} 3 \mathrm{f} 2 \mathrm{~g}$, and $7 \mathrm{~s} 6 \mathrm{p} 6 \mathrm{~d} 3 \mathrm{f} 2 \mathrm{~g}$ quality on hydrogen, first-row, and second-row elements, respectively), whilst the DHDFT calculations, which inherit the slow basis-set convergence of MP2 to some degree, are carried out with the aug'pc-4 basis set $^{63}$ (which is of $7 \mathrm{~s} 6 \mathrm{p} 3 \mathrm{~d} 2 \mathrm{f} 1 \mathrm{~g}, 9 \mathrm{~s} 8 \mathrm{p} 7 \mathrm{~d} 4 \mathrm{f} 3 \mathrm{~g} 2 \mathrm{~h}$, and $8 \mathrm{~s} 7 \mathrm{p} 7 \mathrm{~d} 4 \mathrm{f} 3 \mathrm{~g} 2 \mathrm{~h}$ quality, respectively, on hydrogen, first-row, and second-row elements). The aug'-pc- $n$ basis sets are denoted A'PCn.

The performance of the various DFT and DHDFT procedures when used in conjunction with smaller basis sets is of interest from a practical point of view. This is examined in Section 3.5. The following basis sets are considered: (i) the 6-31+G(d,p), 6$31+\mathrm{G}(2 \mathrm{df}, \mathrm{p})$, and 6-311+G(3df,2p) basis sets of Pople and co-workers; and (ii) the A'VnZ (n $=\mathrm{D}, \mathrm{T})$ correlation-consistent basis sets.

Finally, we note that the mean absolute deviations (MADs) and mean deviations (MDs) presented throughout this manuscript have been calculated with respect to W2.2 and $\mathrm{W} 1$ benchmark values. To enable a rigorous comparison between the benchmark $\mathrm{W} n$ and $\mathrm{DFT} / \mathrm{G} n$ results, all the DFT and $\mathrm{G} n$ calculations are carried out on the B3-LYP/A'VTZ optimized geometries that were used in the W1 and W2.2 calculations.

\section{RESULTS AND DISCUSSION}

3.1 Benchmark Barrier Heights for the WCPT Dataset. The WCPT database is comprised of nine prototypical tautomerization reactions (shown in Figure 1). We have examined these nine tautomerization reactions either: (i) uncatalyzed, (ii) catalyzed by one 
water molecule, or (iii) catalyzed by two water molecules. The W2.2 and W1 barriers for these reactions provide a benchmark set of values that allows the evaluation of the performance of computationally less demanding procedures, both for the uncatalyzed reactions and for any changes that occur as the number of catalytic water molecules is increased.

For the uncatalyzed reactions and for the reactions catalyzed by one water molecule, we were able to obtain W2.2 benchmark barrier heights. For the reactions catalyzed by two water molecules, benchmark barrier heights were obtained by means of the computationally less demanding W1 procedure. We note that for the 18 reactions for which we have both W1 and W2.2 barrier heights, W1 attains an MAD of $0.5 \mathrm{~kJ} \mathrm{~mol}^{-1}$ and an MD of $-0.4 \mathrm{~kJ} \mathrm{~mol}^{-1}$ relative to the W2.2 values (see Table S2 of the Supporting Information for the specific results).

3.2 Overview of the Barrier Heights in the WCPT Dataset. The transition structures for the uncatalyzed reactions are displayed in Figure 2. Our best available benchmark vibrationless barrier heights are given in Table 1 (while Table S3 of the Supporting Information gives the barriers at 0 and $298 \mathrm{~K}$ ). The barrier heights for the uncatalyzed reactions span a wide range: from 130.3 (reaction 7) to 339.9 (reaction 6) kJ $\mathrm{mol}^{-1}$. In general, the barrier heights vary monotonically with the relative strengths of the bonds being broken and formed in the TSs (i.e., $\mathrm{S}-\mathrm{H}<\mathrm{O}-\mathrm{H}<\mathrm{N}-\mathrm{H}<\mathrm{C}-\mathrm{H}$ ). ${ }^{64}$ For example, the proton transfer between an oxygen and a sulfur (reaction 7) has the lowest barrier, whilst the TS involving breakage of two $\mathrm{C}-\mathrm{H}$ bonds has the highest barrier (reaction 6). 


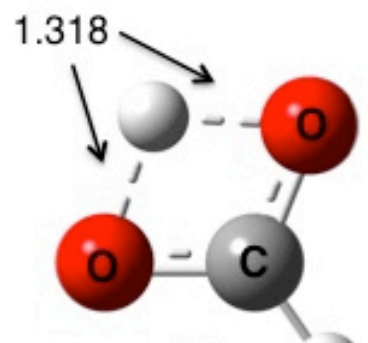

(1)

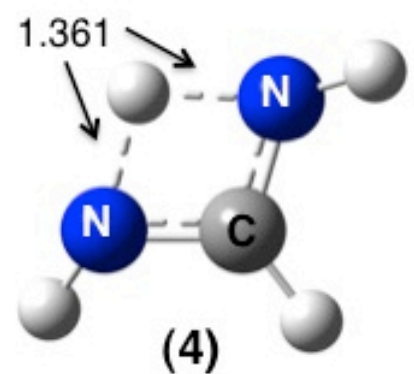

(4)

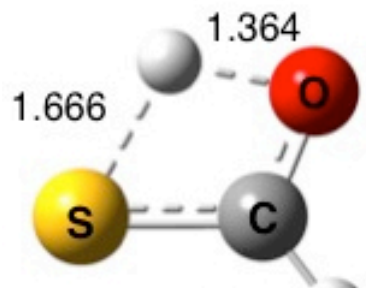

(7)
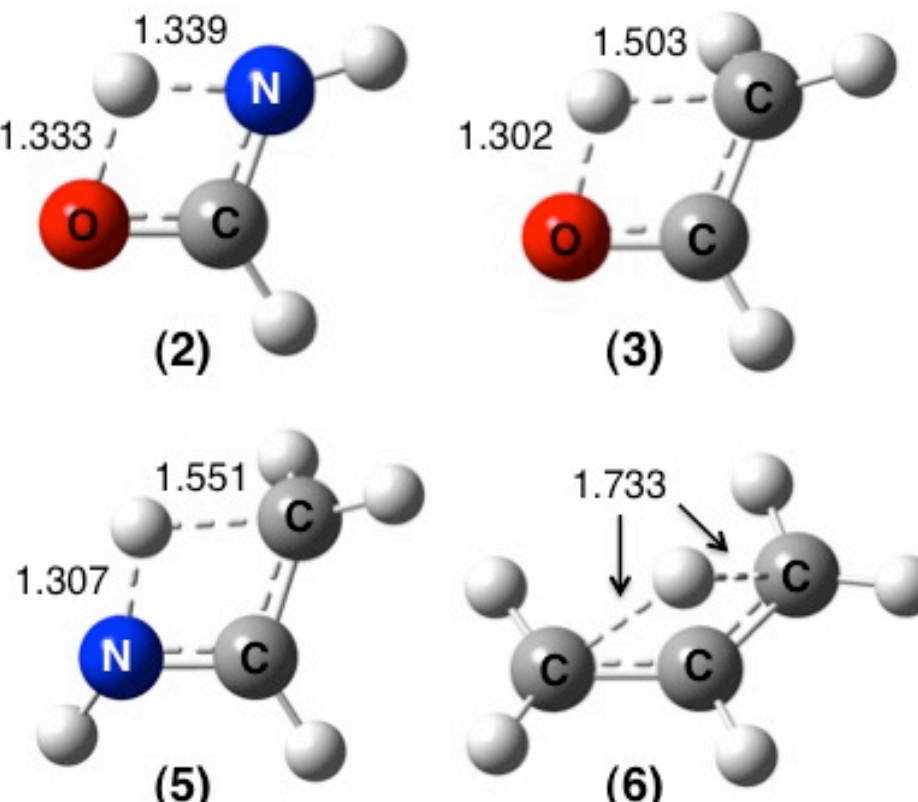

(5)
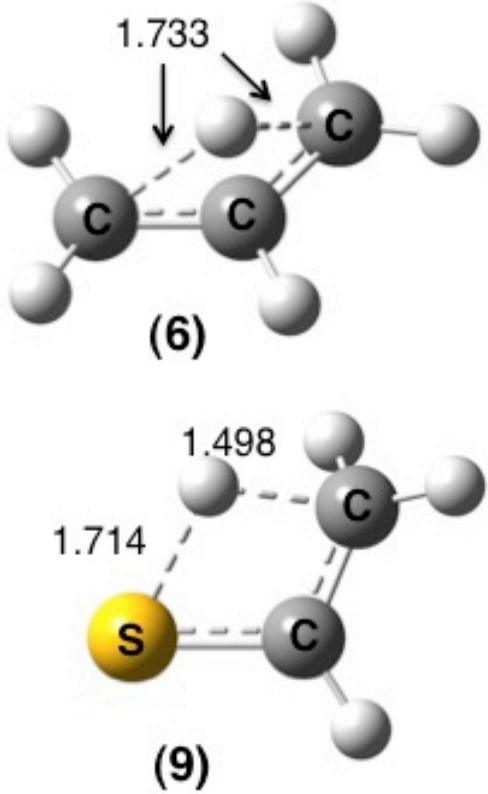

Figure 2. Transition structures for the uncatalyzed reactions in the WCPT dataset. The bonds being broken and formed in the transition structures are represented by single dashed lines, and the lengths of these bonds are given in $\AA$. Atomic color scheme: H, white; C, grey; N, blue; $\mathrm{O}$, red; S, yellow.

The assistance of a single water molecule in the proton transfer drastically reduces the barrier heights, by amounts ranging from 90.4 (reaction 6) to 162.5 (reaction 4) $\mathrm{kJ} \mathrm{mol}^{-1}$. $^{16}$ Figure 3 shows the TSs involving one and two water molecules for these two representative cases. In part, the barrier reductions may be attributed to the reduced strain energy in the TSs, as the addition of a water molecule allows for the formation of a six-membered-ring TS compared with the four-membered-ring TS in the uncatalyzed reaction. 


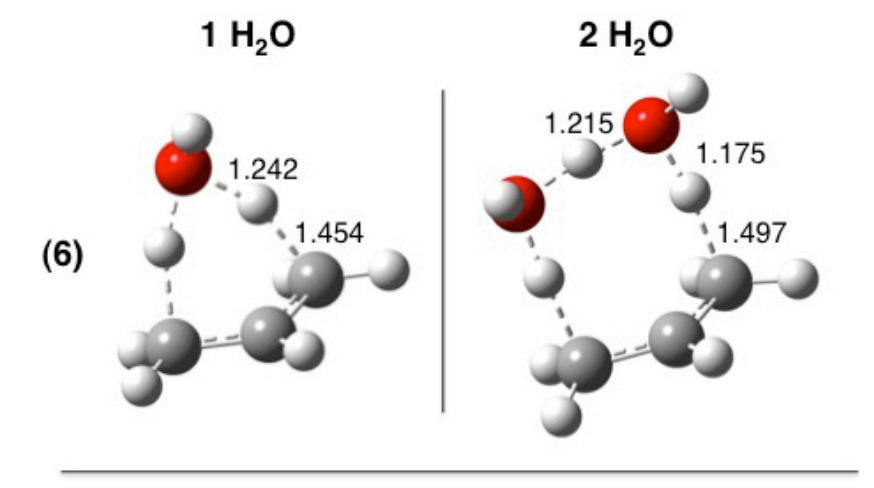

(4)

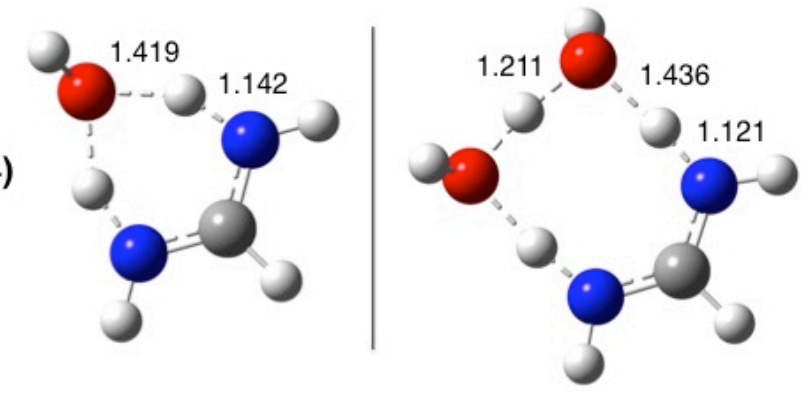

Figure 3. Transition structures for two representative reactions (4 and 6) catalyzed by one and two explicit water molecules. The TS for reaction 4 catalyzed by two water molecules has $\mathrm{C}_{2}$ symmetry, whereas all the other TSs have $\mathrm{C}_{\mathrm{s}}$ symmetry. The color scheme and bond types specified in the caption to Figure 2 apply here (bond lengths are given in $\AA$ ).

Addition of a second water molecule results in a further reduction in the barrier heights, by amounts ranging from 35.1 (reaction 8) to 66.6 (reaction 5) $\mathrm{kJ} \mathrm{mol}^{-1}$ (see Table 1). Again, this may be attributed in part to the reduction in strain energy when moving from a six-membered-ring TS to an eight-membered-ring TS, as well as to the hydrogen bond that is formed between the two water molecules. It should be noted that the ordering of the barrier heights is very similar for the uncatalyzed reactions and for the reactions catalyzed by one and two water molecules. Specifically, in all cases the barriers decrease in the following order: $\mathbf{6}>\mathbf{3}>\mathbf{5}>\mathbf{9}>\mathbf{4} \sim \mathbf{2} \sim \mathbf{8}>\mathbf{1} \sim \mathbf{7}$. Increasing the number of water molecules involved in the catalysis (to three or four molecules) is predicted to further decrease the vibrationless barrier heights. For example, at the G4 level, the following vibrationless barriers are obtained for reaction 1: 154.4 (uncatalyzed), 26.2 (one $\mathrm{H}_{2} \mathrm{O}$ catalyst), -22.2 (two $\mathrm{H}_{2} \mathrm{O}$ catalysts), -44.9 (three $\mathrm{H}_{2} \mathrm{O}$ catalysts), and -63.7 (four $\mathrm{H}_{2} \mathrm{O}$ catalysts) $\mathrm{kJ} \mathrm{mol}^{-1}$. However, on the free energy surface (at $298 \mathrm{~K}$ ) entropic effects come into play and the following barriers are obtained for reaction 1: 144.6 (uncatalyzed), 64.0 (one $\mathrm{H}_{2} \mathrm{O}$ catalyst), 61.1 (two $\mathrm{H}_{2} \mathrm{O}$ catalysts), 77.1 (three $\mathrm{H}_{2} \mathrm{O}$ catalysts), and 100.4 (four $\mathrm{H}_{2} \mathrm{O}$ catalysts) $\mathrm{kJ} \mathrm{mol}^{-1}$. Thus, on the free energy surface, the most significant reduction in the barrier height is provided by the first water catalyst (i.e., the barrier height is reduced by $80.6 \mathrm{~kJ} \mathrm{~mol}^{-1}$ ). Inclusion of a second water catalyst has a minor 
effect (i.e., the barrier height is further reduced by just $2.9 \mathrm{~kJ} \mathrm{~mol}^{-1}$ ), while inclusion of additional water molecules increases the free-energy barrier height.

3.3 Performance of Standard Ab Initio and G4 Procedures. Table 2 gives an overview of the performance of standard ab initio procedures (MP2, SCS-MP2, and MP4), as well as of the composite G4 procedure and variants thereof (G4(MP2) and G4(MP2)-6X). We include only forward barrier heights in the statistical analysis, since the difference between the forward and reverse barrier heights for all reactions is simply the reaction energy for the tautomerization process $(\Delta E)$. The performance of ab initio and DFT procedures for the reaction energies $(\Delta E)$ will be discussed separately in Section 3.6.

Møller-Plesset perturbation theory (MP2 and MP4) tends to overestimate the barrier heights in the "diverse barrier heights" (DBH24/08), "hydrogen-transfer barrier heights" $(\mathrm{HTBH})$, and "nonhydrogen-transfer barrier heights" (NHTBH) datasets of Truhlar and coworkers. ${ }^{66}$ Tautomerization reactions, however, are not generally represented in these datasets. For our set of tautomerization reactions, we find that both MP2 and MP4 systematically underestimate the barriers for the uncatalyzed and catalyzed reactions (as is evident from $\mathrm{MD}=-\mathrm{MAD})$. At the $\mathrm{MP} 2 / \mathrm{A}^{\prime} \mathrm{VQZ}$ level, relatively large MADs of 7.5 (uncatalyzed), 10.4 (one $\mathrm{H}_{2} \mathrm{O}$ catalyst), and 11.7 (two $\mathrm{H}_{2} \mathrm{O}$ catalysts) $\mathrm{kJ} \mathrm{mol}^{-1}$ are obtained. Scaling the same-spin and opposite-spin components of the MP2 correlation energy, as in the SCS-MP2 procedure, seems to overcorrect the deficiencies of MP2, and leads to systematic overestimation of the barrier heights (as is evident from MD = MAD). Note, however, that the MADs for SCS-MP2 are of a similar magnitude to those for MP2. Specifically, they are 4.7 (uncatalyzed), 9.1 (one $\mathrm{H}_{2} \mathrm{O}$ catalyst), and 13.3 (two $\mathrm{H}_{2} \mathrm{O}$ catalysts) $\mathrm{kJ} \mathrm{mol}^{-1}$. Overall, the performance of both MP2 and SCS-MP2 deteriorates with the number of water molecules involved in the catalysis. Inclusion of the higher-order excitations in the MP4 procedure significantly improves the performance for the catalyzed reactions, such that no deterioration in performance is observed as the number of water molecules involved in the catalysis is increased. Specifically, MADs of 5.2, 5.1, and $5.0 \mathrm{~kJ} \mathrm{~mol}^{-1}$ are obtained for the reactions catalyzed by zero, one, and two water molecules, respectively.

The composite G4 procedure and its lower-cost variants (G4(MP2) and G4(MP2)-6X) show excellent performance for the uncatalyzed reactions, with MADs well below the threshold of 'chemical accuracy' (specifically, MAD $=1.5-1.9 \mathrm{~kJ} \mathrm{~mol}^{-1}$ ). The G4 procedure, in which some of the basis-set-correction terms are obtained at the MP4 level, also shows 
very good performance for the catalyzed reactions, with MADs of 3.4 and $4.2 \mathrm{~kJ} \mathrm{~mol}^{-1}$ for the reactions catalyzed by one and two water molecules, respectively. However, the performance of the MP2-based methods significantly deteriorates with the number of water molecules involved in the catalysis. For the reactions catalyzed by one water molecule, MADs of 7.4 (G4(MP2)) and 8.3 (G4(MP2)-6X) kJ mol ${ }^{-1}$ are obtained, while MADs of 12.4 (G4(MP2)) and 13.3 (G4(MP2)-6X) $\mathrm{kJ} \mathrm{mol}^{-1}$ are obtained for the reactions catalyzed by two water molecules. Inspection of the basis-set-correction terms in G4 and G4(MP2) (given in Table $\mathrm{S} 4$ of the Supporting Information) reveals that the $\Delta E(\mathrm{HF})$ term (see eqs 5 and 8 of the Computational Procedures Section) is practically identical in the two cases (the largest difference being $0.3 \mathrm{~kJ} \mathrm{~mol}^{-1}$ ). It is also evident that for the uncatalyzed reactions the $\Delta E(\mathrm{MP} 2)$ basis-set-correction term in G4(MP2) (eq 7) slightly underestimates the sum of the correction terms in G4 (i.e., $\Delta E(+)+\Delta E(2 \mathrm{df}, \mathrm{p})+\Delta E(\mathrm{G} 3$ LargeXP), eqs $2-4)$, but increasingly it overestimates them as more water molecules are involved in the catalysis. This is also evident from the MDs obtained for G4(MP2), namely of -1.1 (uncatalyzed), +7.4 (one $\mathrm{H}_{2} \mathrm{O}$ catalyst), and +12.4 (two $\mathrm{H}_{2} \mathrm{O}$ catalysts) $\mathrm{kJ} \mathrm{mol}^{-1}$.

We examined the effect of adding diffuse functions to the 6-31G(d) basis set used in the $\operatorname{CCSD}(\mathrm{T})$ calculations on the performance of G4(MP2) for the catalyzed reactions (see eqs 6 and 7 of the Computational Procedures Section). A similar modification in the G2+ procedure $^{67}$ was shown to yield better performance for proton transfers involving anionic species. Using the $6-31+\mathrm{G}(\mathrm{d}, \mathrm{p})$ basis set in place of $6-31 \mathrm{G}(\mathrm{d})$ (labeled as $\mathrm{G} 4(\mathrm{MP} 2)(+, \mathrm{p})$ in Table 2) reduces the MAD by $2.2 \mathrm{~kJ} \mathrm{~mol}^{-1}$ for the reactions catalyzed by one water and by $5.5 \mathrm{~kJ} \mathrm{~mol}^{-1}$ for the reactions catalyzed by two waters. We note that using the larger 6$31+\mathrm{G}(2 \mathrm{df}, \mathrm{p})$ basis does not further improve these results.

Another possibility is to calculate the $\triangle E(\mathrm{MP} 2)$ correction term that occurs in G4(MP2) at the MP4 level (i.e., replace $\Delta E(\mathrm{MP} 2)$ with $\Delta E(\mathrm{MP} 4)$, see eqs 7 and 10 ). These results are shown in Table 2 (labeled as G4(MP4)). We can see that G4 and G4(MP4) give essentially the same MADs and MDs for both the catalyzed and uncatalyzed reactions. We note in passing that replacing $\Delta E(\mathrm{MP} 2)$ with a $\Delta E(\mathrm{MP} 3)$ term does not lead to an improvement for the reactions catalyzed by one water molecule, but does lead to an improvement for the reactions catalyzed by two water molecules (see Table 2).

The success of the $\Delta E(\mathrm{MP} n)$ basis-set-correction term in the G4(MPn) procedures (eqs 7 and 10) relies on the following approximation 
where 'small' indicates the smaller basis set used in the $\operatorname{CCSD}(\mathrm{T})$ and $\mathrm{MP} n$ calculations and $\mathrm{MP} n=\mathrm{MP} 2, \mathrm{MP} 3$, or MP4. The results of the previous paragraphs indicate that for the uncatalyzed reactions this approximation holds well with small $=6-31 \mathrm{G}(\mathrm{d})$ and $\mathrm{MP} n=\mathrm{MP} 2$ (i.e., standard G4(MP2)). However, as the number of water molecules involved in the catalysis is increased, one has to either increase the size of the 'small' basis set (e.g., to 6$31+\mathrm{G}(\mathrm{d}, \mathrm{p})$ ) or move to higher-order perturbation theory (MP4). We are currently examining the broader ramifications of these observations.

Finally, we note that, upon removing the MP2-based basis-set-correction term from G4 (i.e., removing the $\Delta E(\mathrm{G} 3$ LargeXP) term, see eq 4, labeled as G4-noMP2 in Table 2), the MAD for the uncatalyzed reactions is increased by $1.2 \mathrm{~kJ} \mathrm{~mol}^{-1}$ (relative to G4). However, the MADs for the catalyzed reactions are improved by 1.1 and $1.7 \mathrm{~kJ} \mathrm{~mol}^{-1}$ (for one and two water molecules catalyzing the reactions, respectively).

3.4 Assessment of DFT Procedures for the WCPT Barrier Heights. Table 3 gives the MADs and MDs from our benchmark $\mathrm{Wn}$ results for a large variety of contemporary DFT and DHDFT procedures. We start by making the following general observations. (i) For the uncatalyzed reactions, the GGA, meta-GGA, and hybrid-GGA functionals tend to systematically underestimate the barrier heights, whilst the rangeseparated GGA and the double-hybrid functionals tend to overestimate the barrier heights. (ii) For the water-catalyzed reactions, nearly all of the functionals tend to systematically underestimate the barrier heights (with the notable exception of BH\&HLYP and BMK). (iii) For most of the functionals, the MAD increases with the number of water molecules involved in the catalysis (i.e., uncatalyzed $<$ one water $<$ two waters).

Of the pure GGAs and meta-GGAs, the only functional that gives MADs lower than $10 \mathrm{~kJ} \mathrm{~mol}^{-1}$ for both the catalyzed and uncatalyzed reactions is M06-L, with MADs of 5.9, 7.8 and $8.3 \mathrm{~kJ} \mathrm{~mol}^{-1}$ for the reactions catalyzed by zero, one, and two water molecules, respectively. The GGA functional HCTH407 shows slightly worse performance for the water-catalyzed reactions (with MADs of 10.2 and $9.3 \mathrm{~kJ} \mathrm{~mol}^{-1}$ for one and two water molecules involved in the catalysis, respectively). However, it gives significantly poorer performance for the uncatalyzed reactions $\left(\mathrm{MAD}=18.0 \mathrm{~kJ} \mathrm{~mol}^{-1}\right)$.

Moving to the hybrid-GGA functionals, we note that X3-LYP, B3-LYP, B97-2, and B97-1 show very good performance for the barriers for the uncatalyzed reactions (MADs of $3.3,3.4,4.8$, and $5.5 \mathrm{~kJ} \mathrm{~mol}^{-1}$, respectively). Of these, only the B97-2 procedure shows 
similar performance for the water-catalyzed reactions, whilst the performance of X3-LYP, B3-LYP, and B97-1 gradually deteriorates with the number of water molecules involved in the catalysis. Note, however, that B3-LYP still gives respectable MADs $\left(\leq 7.3 \mathrm{~kJ} \mathrm{~mol}^{-1}\right)$. The range-separated hybrid-GGA functionals $(\omega \mathrm{B} 97-\mathrm{X}$ and $\omega \mathrm{B} 97)$ show very good performance for the reactions catalyzed by a single water molecule, but their performance is less good for the uncatalyzed reactions (as well as for the reactions catalyzed by two water molecules, see Table 3).

The hybrid-meta-GGA procedures can be divided into two categories: (i) procedures for which the performance drastically deteriorates with the number of water molecules that catalyze the reaction (namely, M06-2X, $\tau-\mathrm{HCTH}$, and M06-HF), and (ii) procedures for which the performance does not significantly deteriorate with the number of water molecules involved in the catalysis (namely, PW6-B95, M06, B1-B95, and BMK). The procedures within the first category systematically underestimate the barrier heights for the catalyzed reactions (i.e., $\mathrm{MD}=-\mathrm{MAD}$ ). However, the procedures within the second category tend to either underestimate the barrier heights to a lesser extent or even to overestimate them, something more pronounced when two water molecules catalyze the reaction. Of these functionals, PW6-B95 shows the best overall performance, with MADs of 4.5, 5.9 and $5.7 \mathrm{~kJ}$ $\mathrm{mol}^{-1}$ for the reactions catalyzed by zero, one, and two water molecules, respectively. We note in passing that this functional was also found to be one of the best hybrid-meta-GGA procedures in terms of overall performance for the 30 reference datasets in the GMTKN30 general-purpose database of Goerigk and Grimme. ${ }^{68}$

All of the double-hybrid functionals show excellent performance for the treatment of both the uncatalyzed and water-catalyzed reactions. For the reactions catalyzed by zero, one, and two water molecules, MADs in the following ranges are obtained: 1.7-3.9, 2.7-3.8, and 3.4-4.3 $\mathrm{kJ} \mathrm{mol}^{-1}$, respectively (excluding the B2-PLYP functional which performs rather well for the uncatalyzed reactions, but less so for the catalyzed reactions). More specifically, for the uncatalyzed reactions DSD-PLYP and B2T-PLYP exhibit the best performance (MAD = 1.7 and $1.8 \mathrm{~kJ} \mathrm{~mol}^{-1}$, respectively). For the reactions catalyzed by a single water molecule, B2K-PLYP and ROB2-PLYP show the best performance (MADs $=2.7$ and $2.9 \mathrm{~kJ} \mathrm{~mol}^{-1}$, respectively). The same two functionals also exhibit the best performance for reactions catalyzed by two water molecules (MAD $=3.4 \mathrm{~kJ} \mathrm{~mol}^{-1}$ for both procedures).

Finally, a word is due on empirical London-dispersion corrections for the DFT energies (denoted by the suffix “-D3"). ${ }^{69}$ These are listed in Table S5 of the Supporting 
Information, while Table 4 presents for a number of representative DFT procedures the differences between the MAD obtained for the DFT procedure without the dispersion correction (as given in Table 3) and the MAD obtained for the DFT-D3 procedure: $\triangle \mathrm{MAD}=$ MAD(DFT-D3) - MAD(DFT). The dispersion corrections to the barriers for the uncatalyzed reactions are rather modest, e.g., for the B3-LYP functional they range from -0.1 to $+0.9 \mathrm{~kJ}$ $\mathrm{mol}^{-1}$ (Table S5). For the catalyzed reactions, larger dispersion corrections are obtained due to the fact that weak interactions are more pronounced in the transition structures than in the separated reactants. Furthermore, since dispersion corrections are always attractive, they systematically reduce the barriers. For example, the empirical D3 dispersion corrections (for the B3-LYP functional) reduce the barriers for the reactions catalyzed by one water molecule by $5.0-9.1 \mathrm{~kJ} \mathrm{~mol}^{-1}$, while for the reactions catalyzed by two water molecules the barriers are reduced by as much as $13.5-18.8 \mathrm{~kJ} \mathrm{~mol}^{-1}$. Therefore, in cases where the DFT procedure underestimates the absolute barriers, the dispersion correction will further increase the deviation from the $\operatorname{CSSD}(\mathrm{T}) / \mathrm{CBS}$ limit barriers. Replacing the zero-damping function in the standard D3 procedure with the finite 'Becke-Johnson' damping function leads to similar results (see Table S6 of the Supporting Information). ${ }^{70}$

3.5 Basis Set Convergence of DFT Procedures. Table 5 gives an overview of the basis-set convergence for the DFT procedures. The following basis sets are considered: (i) Pople's 6-31+G(d,p), 6-31+G(2df,p), and 6-311+G(3df,2p) basis sets; and (ii) Dunning's $\mathrm{A}^{\prime} \mathrm{VDZ}$ and $\mathrm{A}^{\prime} \mathrm{VTZ}$ correlation-consistent basis sets. The tabulated values give the difference between the MADs obtained with the A'PC3 or A'PC4 basis sets (reported in Table 3) and those obtained with the specified smaller basis sets, $\triangle \mathrm{MAD}=\mathrm{MAD}($ small basis set) MAD(large basis set). Thus, a negative $\triangle \mathrm{MAD}$ indicates that the use of the smaller basis results in an overall improvement in the performance of the functional, whereas a positive value indicates a worse performance with the smaller basis. Inspection of Table 5 reveals that, unsurprisingly, the smaller basis sets that we have examined generally result in positive $\triangle$ MADs, which become increasingly large as the number of water molecules that catalyze the reaction is increased.

Let us start with the basis-set dependence of the conventional DFT procedures. For the uncatalyzed reactions, the $6-31+\mathrm{G}(\mathrm{d}, \mathrm{p})$ basis leads to improvements in the MADs by $1-2$ $\mathrm{kJ} \mathrm{mol}^{-1}$ for most of the functionals, whilst for the catalyzed reactions large positive $\triangle \mathrm{MADs}$ are seen (typically, $\triangle \mathrm{MAD}=5-10$ and $10-20 \mathrm{~kJ} \mathrm{~mol}^{-1}$ for the reactions catalyzed by one and 
two water molecules, respectively). Inclusion of a set of $\mathrm{d}$ and $\mathrm{f}$ functions in the basis set (i.e., $6-31+\mathrm{G}(2 \mathrm{df}, \mathrm{p}))$ results in MADs that are very close to those obtained with the large basis set for the uncatalyzed reactions. This also improves the situation for the reactions catalyzed by one and two water molecules. However, positive $\triangle$ MADs of 2-5 and 5-10 $\mathrm{kJ} \mathrm{mol}^{-1}$, respectively, are still observed in most cases. Moving to the triple-zeta-valence 6$311+\mathrm{G}(3 \mathrm{df}, 2 \mathrm{p})$ basis, for the reactions catalyzed by zero and one water molecule the MADs are close to those obtained with the large basis set, whilst for the reactions catalyzed by two water molecules $\triangle \mathrm{MADs}$ ranging between $2-4 \mathrm{~kJ} \mathrm{~mol}^{-1}$ are observed. The correlationconsistent $\mathrm{A}^{\prime} \mathrm{VDZ}$ and $\mathrm{A}^{\prime} \mathrm{VTZ}$ basis sets generally show performances similar to those of the $6-31+\mathrm{G}(2 \mathrm{df}, \mathrm{p})$ and 6-311+G(3df,2p) basis sets, respectively.

In general, the performance of the double-hybrid procedures in conjunction with the Pople-style basis sets is similar to that with the A'PC4 basis set. This is true for all the basis sets apart from the relatively small $6-31+\mathrm{G}(\mathrm{d}, \mathrm{p})$ basis. For example, for $6-31+\mathrm{G}(2 \mathrm{df}, \mathrm{p})$ and 6$311+\mathrm{G}(3 \mathrm{df}, 2 \mathrm{p}), \Delta \mathrm{MADs}$ of less than $+2.7 \mathrm{~kJ} \mathrm{~mol}^{-1}$ are found for the reactions catalyzed by zero and two water molecules, whereas for the reactions catalyzed by one water molecule these two basis sets result in near-zero $\triangle$ MADs. For the Dunning basis sets, the $\triangle \mathrm{MAD}$ increases with the number of water molecules involved in the catalysis. For example, for the $\mathrm{A}^{\prime} \mathrm{VDZ}$ basis set $\triangle \mathrm{MADs}$ of about $\sim 0,1-4$, and $3-5 \mathrm{~kJ} \mathrm{~mol}^{-1}$ are found for the reactions catalyzed by zero, one, and two water molecules, respectively.

\subsection{Performance of the Ab Initio and DFT Procedures for the Reaction}

Energies. Table 6 gives an overview of the performance of the theoretical procedures that were considered in Tables 2 and 3 for the reactions energies in the WCPT dataset. The nonrelativistic, all-electron, vibrationless $\operatorname{CCSD}(\mathrm{T}) / \mathrm{CBS}$ benchmark values were obtained with the W2.2 procedure and are given Table 1 (while Table S7 of the Supporting Information gives the reaction energies at 0 and $298 \mathrm{~K}$ ). Inspection of Table 6 quickly reveals that almost all of the theoretical procedures considered perform very well for the reaction energies. In particular, MP2, SCS-MP2, and MP4 show comparable performance, with MADs of 2.8-3.2 $\mathrm{kJ} \mathrm{mol}^{-1}$. Of the G4 family, G4(MP2) gives the best performance with an MAD of just $1.3 \mathrm{~kJ} \mathrm{~mol}^{-1}$. The MADs for the DHDFT procedures cluster within a very narrow range (2.9-3.3 kJ mol${ }^{-1}$ ). With few exceptions (most notably M06-HF and M06-L), the standard DFT procedures attain MADs below or near the threshold of 'chemical accuracy'. Of the hybrid-meta-GGAs, PW6-B95, B1-B95, and M06-2X exhibit the best 
performance $\left(\mathrm{MADs}=3.5-3.6 \mathrm{~kJ} \mathrm{~mol}^{-1}\right.$ ), whilst the best performing hybrid-GGAs are BH\&HLYP, B97-1, X3-LYP, PBE0, and B3-LYP (MADs $\left.=3.8-4.0 \mathrm{~kJ} \mathrm{~mol}^{-1}\right)$.

\section{CONCLUDING REMARKS}

We have obtained benchmark barrier heights by means of the high-level W2.2 (or W1 for the larger systems) composite thermochemistry protocols, and used these to evaluate the performance of a variety of MPn, G4-type, and density functional theory procedures in predicting barrier heights for uncatalyzed and water-catalyzed proton-transfer tautomerization reactions.

With regard to the performance of the G4-type procedures, we draw the following conclusions:

(i) G4 shows good performance for the uncatalyzed reactions (MAD $=1.8 \mathrm{~kJ}$ $\left.\mathrm{mol}^{-1}\right)$, reactions catalyzed by one water molecule $\left(\mathrm{MAD}=3.4 \mathrm{~kJ} \mathrm{~mol}^{-1}\right)$, and reactions catalyzed by two water molecules $\left(\mathrm{MAD}=4.2 \mathrm{~kJ} \mathrm{~mol}^{-1}\right)$.

(ii) G4(MP2) and G4(MP2)-6X show good performance for the uncatalyzed reactions $\left(\mathrm{MADs}=1.9\right.$ and $1.5 \mathrm{~kJ} \mathrm{~mol}^{-1}$, respectively). However, their performance significantly deteriorates with the number of water molecules involved in the catalysis (MADs of 12.4 and $13.3 \mathrm{~kJ} \mathrm{~mol}^{-1}$, respectively, for the reactions with two water molecules).

(iii) This deterioration in performance is associated with the inadequacy of the basis-set-correction term used in G4(MP2) for the catalyzed reactions.

The performance of a large variety of contemporary DFT and DHDFT procedures was also evaluated for the calculation of barrier heights for the uncatalyzed and catalyzed reactions. We make the following observations:

(i) With few exceptions, the standard functionals (rungs 1-4 on Jacob's Ladder) that show good performance for the uncatalyzed reactions perform less well as the number of water molecules involved in the catalysis is increased.

(ii) Notable exceptions are PW6-B95 $\left(\right.$ MADs $\left.=4.5-5.9 \mathrm{~kJ} \mathrm{~mol}^{-1}\right)$, B97-2 $($ MADs $\left.=4.8-6.3 \mathrm{~kJ} \mathrm{~mol}^{-1}\right)$, and B3-LYP $\left(\mathrm{MADs}=3.4-7.3 \mathrm{~kJ} \mathrm{~mol}^{-1}\right)$.

(iii) The double-hybrid DFT procedures attain MADs below the threshold of 'chemical accuracy' (with the exception of B2-PLYP which gives slightly 
higher MADs). ROB2-PLYP and B2K-PLYP show the best overall performance.

\section{- ASSOCIATED CONTENT}

- Supporting Information. Diagnostics indicating the importance of nondynamical correlation effects in the uncatalyzed and catalyzed transition structures (Table S1); overview of the performance of $\mathrm{W} 1$ relative to $\mathrm{W} 2.2$ (Table S2); W1 and W2.2 barrier heights at 0 and $298 \mathrm{~K}$ (Table S3); components of G4 and variants thereof (Table S4); empirical D3 dispersion corrections for a number of DFT procedures (Table S5); statistical analysis for the performance of the Becke-Johnson damping function in the D3 dispersion corrections (Table S6); W2.2 reaction energies at 0 and $298 \mathrm{~K}$ for the reactions in the WCPT dataset (Table S7); and B3-LYP/A'VTZ optimized geometries for all the species in the WCPT dataset (Table S8). Full references for the Gaussian 09 and Molpro 2010 program suites (Table S9). This material is available free of charge via the Internet at http://pubs.acs.org.

\section{AUTHOR INFORMATION}

\section{Corresponding Author}

*E-Mail: amir.karton@chem.usyd.edu.au; radom@chem.usyd.edu.au

\section{ACKNOWLEDGMENT}

We gratefully acknowledge funding (to AK and LR) from the Australian Research Council, the provision of an Australian Postgraduate Award (to RJO), and the generous allocation of computing time from the National Computational Infrastructure (NCI) National Facility and from Intersect Australia Ltd.

\section{- REFERENCES}

${ }^{1}$ (a) Lill, M. A.; Helms, V. Proc. Natl. Acad. Sci. 2002, 99, 2778-2781. (b) Cui, Q.; Karplus, M. J. Phys. Chem. B 2002, 106, 7927-7947. (c) Douhal, A.; Kim, S. K.; Zewail, A. H. Nature 1995, 378, 260-263. (d) Copeland, R. A.; Chan, S. I. Annu. Rev. Phys. Chem. 1989, 40, 671-698.

${ }^{2}$ IUPAC. Compendium of Chemical Terminology, 2nd ed. (the "Gold Book"). Compiled by A. D. McNaught and A. Wilkinson. Blackwell Scientific Publications, Oxford (1997). XML on-line corrected version: http://goldbook.iupac.org (2006-) created by M. Nic, J. Jirat, B. Kosata; updates compiled by A. Jenkins. ISBN 0-9678550-9-8.

${ }^{3}$ (a) Kwiatkowski, J. S.; Pullman, B. Adv. Het. Chem. 1975, 18, 199. (b) Topal, M. D.; Fresco, J. R. Nature 1976, 263, 285-289. 
${ }^{4}$ Assary, R. S.; Redfern, P. C.; Greeley, J.; Curtiss, L. A. J. Phys. Chem. B 2011, 115, 43414349.

${ }^{5}$ Tsipis, C. A.; Karipidis, P. A. J. Am. Chem. Soc. 2002, 125, 2307-2318.

${ }^{6}$ Bell, R. L.; Taveras, D. L.; Troung, T. N.; Simons, J. Int, J. Quantum. Chem. 1996, 63, 861-874.

${ }^{7}$ Delchev, V. B.; Mikosch, H. J. Mol. Modeling 2006, 12, 229-236.

${ }^{8}$ Liang, X.; Pu, X.; Zhou, H.; Wong, N.-B.; Tian, A. J, Mol. Struct. THEOCHEM 2007, 816, $125-136$.

${ }^{9}$ Liang, X.; Zheng, W.; Wong, N.-B.; Shu, Y.; Tian, A. J. Mol. Struct. THEOCHEM 2005, $732,127-137$.

${ }^{10} \mathrm{Hu}$, X.; Li, H.; Zhang, L.; Han, S. J. Phys. Chem. B 2007, 111, 9347-9354.

${ }^{11}$ Ruangpornvisuti, V.; Supakornchailert K.; Tungchitpienchai, C.; Wanno, B. Struct. Chem. 2007, 18, 555-561.

${ }^{12}$ Li, Q.-G.; Xue, Y.; Yan, G.-S. J. Mol. Struct. THEOCHEM 2008, 868, 55-64.

${ }^{13}$ Alagona, G.; Ghio, C.; Nagy, P. I. Phys. Chem. Chem. Phys. 2010, 12, 10173-10188.

${ }^{14}$ Lie, M. A.; Schiott, B. J. Comput. Chem. 2008, 29, 1037-1047.

${ }^{15}$ For a comprehensive review of catalyzed and uncatalyzed tautomerization reactions see:

Raczy ska, E. D.; Kosi ska W.; O mia owski B.; Gawinecki R. Chem. Rev. 2005, 105, 35613612.

16 The tautomerization reactions that we have considered are likely to represent a spectrum of possibilities. In some cases (e.g., reaction 6 in which the hydrogen is transferred between two carbon atoms), they may be more appropriately described as hydrogen-transfer reactions, whereas in others (e.g., keto-enol and amide-imidol in which the hydrogen/proton is transferred between two electronegative elements), they may be more appropriately described as proton-transfer reactions. For simplicity, we shall use the proton-transfer description throughout.

${ }^{17}$ Dunning, T. H. J. Chem. Phys. 1989, 90, 1007-1023.

${ }^{18}$ Kendall, R. A.; Dunning, T. H.; Harrison, R. J. J. Chem. Phys. 1992, 96, 6796-9806.

${ }^{19}$ Dunning, T. H. Jr; Peterson, K. A.; Wilson, A. K. J. Chem. Phys. 2001, 114, 9244-9253.

${ }^{20}$ Gaussian 09, Revision A.1, Frisch, M. J.; Trucks, G. W.; Schlegel, H. B.; Scuseria, G. E.; Robb, M. A.; Cheeseman, J. R.; Scalmani, G.; Barone, V.; Mennucci, B.; Petersson, G. A.; et al. Gaussian, Inc., Wallingford CT, 2009.

${ }^{21}$ MOLPRO 2009.1, Werner, H.-J.; Knowles, P. J.; Lindh, R.; Manby, F. R.; Schütz, M.; Celani, P.; Korona, T.; Mitrushenkov, A.; Rauhut, G.; B. Adler, T.; et al. see: http:www.molpro.net.

${ }^{22}$ Karton, A.; Rabinovich, E.; Martin, J. M. L.; Ruscic, B. J. Chem. Phys. 2006, 125, 144108.

${ }^{23}$ Martin, J. M. L.; Oliveira, G. J. Chem. Phys. 1999, 111, 1843.

${ }^{24}$ Karton, A.; Daon, S.; Martin, J. M. L. Chem. Phys. Lett. 2011, 510, 165-178.

${ }^{25}$ The experimental atomization energies are obtained from the Active Thermochemical

Tables (ATcT) thermochemical network, and are associated with 95\% confidence intervals of $0.2 \mathrm{~kJ} \mathrm{~mol}^{-1}$. For further details, see reference 24 and references therein.

${ }^{26}$ Peterson, K. A.; Dunning, T. H. J. Chem. Phys. 2002, 117, 10548.

${ }^{27}$ Grimme, S. J. Chem. Phys. 2003, 118, 9095(1-9).

${ }^{28}$ Curtiss, L. A.; Redfern, P. C.; Raghavachari, K. J. Chem. Phys. 2007, 126, 084108(1-12).

${ }^{29}$ Curtiss, L. A.; Redfern, P. C.; Raghavachari, K. J. Chem. Phys. 2007, 127, 124105(1-8).

${ }^{30}$ Chan, B.; Deng, J.; Radom, L. J. Chem. Theory Comput. 2011, 7, 112-120.

${ }^{31}$ Perdew, J.P.; Schmidt, K. AIP Conf. Proc. 2001, 577, 1.

${ }^{32}$ Becke, A. D. Phys. Rev. A 1988, 38, 3098-3100. 
${ }^{33}$ Lee, C.; Yang, W.; Parr, R. G. Phys. Rev. B 1988, 37, 785-789.

${ }^{34}$ Perdew, J. P. Phys. Rev. B 1986, 33, 8822-8824.

${ }^{35}$ (a) Perdew, J. P.; Burke, K.; Ernzerhof, M. Phys. Rev. Lett. 1996, 77, 3865-3868. (b) Erratum: Phys. Rev. Lett. 1997, 78, 1396.

${ }^{36}$ Boese, A. D.; Handy, N. C. J. Chem. Phys. 2001, 114, 5497-5503.

${ }^{37}$ Grimme, S. J. Comp. Chem. 2006, 27, 1787-1799.

${ }^{38}$ van Voorhis, T.; Scuseria, G. E. J. Chem. Phys. 1998, 109, 400-410.

39 Tao, J. M.; Perdew, J. P.; Staroverov, V. N.; Scuseria, G. E. Phys. Rev. Lett. 2003, 91, 146401(1-4).

${ }^{40}$ Boese, A. D.; Handy, N. C. J. Chem. Phys. 2002, 116, 9559-9569.

${ }^{41}$ Zhao, Y.; Truhlar, D. G. J. Chem. Phys. 2006, 125, 194101(1-18).

${ }^{42}$ Adamo, C.; Barone, V. J. Chem. Phys. 1999, 110, 6158-6170.

${ }^{43}$ Perdew, J. P.; Chevary, J. A.; Vosko, S. H.; Jackson, K. A.; Pederson, M. R.; Singh, D. J.; Fiolhais, C. Phys. Rev. B 1992, 46, 6671-6687.

${ }^{44}$ Becke, A. D. J. Chem. Phys. 1993, 98, 5648-5652.

${ }^{45}$ Hamprecht, F. A.; Cohen, A. J.; Tozer, D. J.; Handy, N. C. J. Chem. Phys. 1998, 109, 6264-6271.

${ }^{46}$ Schmider, H. L.; Becke, A. D. J. Chem. Phys. 1998, 108, 9624-9631.

${ }^{47}$ Staroverov, V. N.; Scuseria, G. E.; Tao, J.; Perdew, J. P. J. Chem. Phys. 2003, 119, 1212912137.

${ }^{48}$ Stephens, P. J.; Devlin, F. J.; Chabalowski, C. F.; Frisch, M. J. J. Phys. Chem. 1994, 98, $11623-11627$.

${ }^{49}$ Xu, X.; Zhang, Q.; Muller, R. P.; Goddard, W. A., III J. Chem. Phys. 2005, 122, 014105(114).

${ }^{50}$ Becke, A. D. J. Chem. Phys. 1993, 98, 1372-1377.

${ }^{51}$ Chai, J.-D.; Head-Gordon, M. J. Chem. Phys. 2008, 128, 084106(1-15).

${ }^{52}$ Chai, J.-D.; Head-Gordon, M. Phys. Chem. Chem. Phys. 2008, 10, 6615-6620.

${ }^{53}$ Becke, A. D. J. Chem. Phys. 1996, 104, 1040-1046.

${ }^{54}$ Boese, A. D.; Martin, J. M. L. J. Chem. Phys. 2004, 121, 3405-3416.

${ }^{55}$ Zhao, Y.; Schultz, N. E.; Truhlar, D. G. J. Chem. Phys. 2005, 123, 161103(1-4).

${ }^{56}$ Zhao, Y.; Schultz, N. E.; Truhlar, D. G. J. Chem. Theory Comput. 2006, 2, 364-382.

${ }^{57}$ Zhao, Y.; Truhlar, D. G. Theor. Chem. Acc. 2008, 120, 215-241.

${ }^{58}$ Grimme, S. J. Chem. Phys. 2006, 124, 034108(1-16).

${ }^{59}$ Tarnopolsky, A.; Karton, A.; Sertchook, R.; Vuzman, D.; Martin, J. M. L. J. Phys. Chem. A 2008, 112, 3-8.

${ }^{60}$ Karton, A.; Tarnopolsky, A. Lamere, J.-F.; Schatz, G. C.; Martin, J. M. L. J. Phys. Chem. A 2008, 112, 12868-12886.

${ }^{61}$ Graham, D. C.; Menon, A. S.; Goerigk, L.; Grimme, S.; Radom, L. J. Phys. Chem. A, 2009, 113, 9861-9873.

${ }^{62}$ Kozuch, S.; Gruzman, D.; Martin, J. M. L. J. Phys. Chem. C 2010, 114, 20801-20808.

${ }^{63}$ (a) Jensen, F. J. Chem. Phys. 2001, 115, 9113-9125. (b) Erratum 2002, 116, 3502.

${ }^{64}$ Luo, Y.-R. Comprehensive Handbook of Chemical Bond Energies; Taylor \& Francis: Boca Raton, FL, 2007, and references therein.

${ }^{65}$ Zheng, J.; Zhao, Y; Truhlar, D. G. J. Chem. Theory Comput. 2009, 5, 808-821.

${ }^{66}$ (a) Zheng, J.; Zhao, Y; Truhlar, D. G. J. Chem. Theory Comput. 2007, 3, 569-582. (b)

Zhao, Y; González-García, N.; Truhlar, D. G. J. Phys. Chem. A 2005, 109, 2012-2018.

${ }^{67}$ (a) Gronert, S. J. Am. Chem. Soc. 1993, 115, 10258-10266. (b) Gronert, S. Chem. Phys.

Lett. 1996, 252, 415-418. 
${ }^{68}$ Goerigk, L.; Grimme, S. Phys. Chem. Chem. Phys. 2011, 13, 6670-6688.

${ }^{69}$ Grimme, S.; Antony, J.; Ehrlich, S.; Krieg, H. J. Chem. Phys. 2010, 132, 154104(1-19).

${ }^{70}$ Grimme, S.; Ehrlich, S.; Goerigk, L. J. Comput. Chem. 2011, 32, 1456-1465. 
Table 1. Nonrelativistic, All-Electron, Vibrationless CCSD(T) Basis-Set-Limit Barrier Heights $\left(\Delta E^{\ddagger}\right)$ and Reaction Energies $\left(\Delta E_{r}\right)$ for the Reactions in the WCPT Dataset (Obtained Using W2.2 and W1, $\Delta E^{\ddagger_{e}}$ in $\left.\mathrm{kJ} \mathrm{mol}^{-1}\right)^{a}$

\begin{tabular}{|c|c|c|c|c|}
\hline \multirow[t]{3}{*}{ Reaction } & & \multicolumn{3}{|c|}{ Catalyst } \\
\hline & & Uncat. $^{b}$ & $1 \mathrm{H}_{2} \mathrm{O}^{b}$ & $2 \mathrm{H}_{2} \mathrm{O}^{c, d}$ \\
\hline & $\Delta E_{r^{b, e}}^{b}$ & & $\Delta E^{\ddagger}$ & \\
\hline 1 & 0 & 153.8 & 22.6 & -26.7 \\
\hline 2 & 45.2 & 196.7 & 56.4 & 11.2 \\
\hline 3 & 38.3 & 293.3 & 158.7 & 99.2 \\
\hline 4 & 0 & 198.8 & 36.3 & -17.1 \\
\hline 5 & 12.3 & 287.1 & 154.1 & 87.5 \\
\hline 6 & 0 & 339.9 & 249.5 & 207.0 \\
\hline 7 & -3.6 & 130.3 & 20.8 & -19.4 \\
\hline 8 & 46.6 & 167.8 & 61.4 & 26.3 \\
\hline 9 & 10.2 & 256.2 & 149.2 & 85.5 \\
\hline
\end{tabular}

${ }^{a}$ The barrier heights are calculated relative to the isolated species.

${ }^{b}$ Reference values from W2.2.

${ }^{c}$ Reference values from $\mathrm{W} 1$.

${ }^{d}$ The barriers for reactions $\mathbf{1}, \mathbf{4}$, and $\mathbf{7}$ are negative on the electronic surface (both at the W1 and B3-LYP/A'VTZ levels of theory). However, on the B3-LYP/A'VTZ free energy surface, all the barrier heights are positive, with reaction 1 being associated with the lowest barrier $\left(49.6 \mathrm{~kJ} \mathrm{~mol}^{-1}\right)$.

${ }^{e}$ The reaction energies of reactions $\mathbf{1}, \mathbf{4}$, and $\mathbf{6}$ are zero by definition. 
Table 2. Statistical Analysis for the Performance of Conventional and Composite Ab Initio Procedures for the Calculation of the Barrier Heights in the WCPT Database (in $\mathrm{kJ} \mathrm{mol}^{-1}$ )

\begin{tabular}{|c|c|c|c|c|c|c|}
\hline & & & \multicolumn{4}{|c|}{ Catalyst } \\
\hline & \multicolumn{2}{|c|}{ Uncat. $^{a}$} & \multicolumn{2}{|c|}{$1 \mathrm{H}_{2} \mathrm{O}^{a}$} & \multicolumn{2}{|c|}{$2 \mathrm{H}_{2} \mathrm{O}^{b}$} \\
\hline & MAD & MD & MAD & MD & MAD & MD \\
\hline $\mathrm{MP}^{c}$ & 7.5 & -7.5 & 10.4 & -10.4 & 11.7 & -11.7 \\
\hline SCS-MP2 ${ }^{c}$ & 4.7 & 4.7 & 9.1 & 9.1 & 13.3 & 13.3 \\
\hline $\mathrm{MP}^{c}$ & 5.2 & -5.2 & 5.1 & -5.1 & 5.0 & -5.0 \\
\hline G4(MP2)-6X & 1.5 & 0.6 & 8.3 & 8.3 & 13.3 & 13.3 \\
\hline G4(MP2) & 1.9 & -1.1 & 7.4 & 7.4 & 12.4 & 12.4 \\
\hline $\mathrm{G} 4(\mathrm{MP} 2)(+, \mathrm{p})^{d}$ & 1.8 & 0.7 & 5.2 & 5.2 & 6.9 & 6.9 \\
\hline G4(MP3) $)^{e}$ & 3.4 & 2.4 & 7.7 & 7.7 & 9.0 & 9.0 \\
\hline G4(MP4) & 1.4 & 0.4 & 3.4 & 3.4 & 4.4 & 4.4 \\
\hline $\mathrm{G} 4(\mathrm{MP} 4)(+, \mathrm{p})^{d, f}$ & 1.6 & 0.9 & 3.8 & 3.8 & 4.5 & 4.5 \\
\hline G4-noMP2 $2^{g}$ & 3.0 & 2.9 & 2.3 & 1.8 & 2.5 & 0.8 \\
\hline G4 & 1.8 & 1.2 & 3.4 & 3.4 & 4.2 & 4.2 \\
\hline
\end{tabular}

${ }^{a}$ Reference values from W2.2.

${ }^{b}$ Reference values from $\mathrm{W} 1$.

${ }^{c}$ Calculated with the $\mathrm{A}^{\prime} \mathrm{VQZ}$ basis set.

${ }^{d}$ Calculating the base $\operatorname{CCSD}(\mathrm{T})$ energy in G4(MP2) with the 6-31+G(d,p) basis set, see text and eqs 6 and 7.

${ }^{e} \mathrm{Same}$ as G4(MP2), but with $n=3$ rather than 2 in the $\Delta \mathrm{E}(\mathrm{MP} n)$ term, see text and eq 10 .

${ }^{f} \mathrm{Same}$ as G4(MP2), but with $n=4$ rather than 2 in the $\Delta \mathrm{E}(\mathrm{MP} n)$ term, see text and eq 10 .

${ }^{g} \mathrm{G} 4$ without the $\Delta \mathrm{E}(\mathrm{G} 3 \mathrm{LargeXP})$ term, see text and eq 4 . 
Table 3. Statistical Analysis for the Performance of DFT Procedures for the Calculation of the Barrier Heights in the WCPT Database (in $\mathrm{kJ} \mathrm{mol}^{-1}$ )

\begin{tabular}{llcccccc} 
& & \multicolumn{2}{c}{ Uncat. $^{c}$} & \multicolumn{2}{c}{$1^{2} \mathrm{H}_{2} \mathrm{O}^{c}$} & \multicolumn{2}{c}{$2 \mathrm{H}_{2} \mathrm{O}^{d}$} \\
Functional $^{a}$ & Type $^{b}$ & MAD & MD & MAD & MD & MAD & MD \\
HCTH407 & GGA & 18.0 & -18.0 & 10.2 & -6.4 & 9.3 & -0.9 \\
B-LYP & GGA & 17.4 & -17.4 & 15.5 & -15.5 & 15.0 & -15.0 \\
B97-D & GGA & 16.2 & -16.2 & 20.0 & -20.0 & 26.3 & -26.3 \\
PBE & GGA & 30.0 & -30.0 & 40.5 & -40.5 & 48.1 & -48.1 \\
M06-L & MGGA & 5.9 & -5.4 & 7.8 & -4.9 & 8.3 & -3.2 \\
$\tau$-HCTH & MGGA & 18.9 & -18.9 & 21.7 & -21.7 & 24.9 & -24.9 \\
TPSS & MGGA & 18.8 & -18.8 & 23.7 & -23.7 & 25.6 & -25.6 \\
B97-2 & HGGA & 4.8 & -4.0 & 6.3 & -3.7 & 5.4 & 0.4 \\
B3-LYP & HGGA & 3.4 & -1.3 & 6.5 & -5.8 & 7.3 & -7.1 \\
X3-LYP & HGGA & 3.3 & -0.6 & 8.3 & -8.3 & 12.4 & -12.4 \\
B97-1 & HGGA & 5.5 & -5.4 & 12.3 & -12.3 & 15.3 & -15.3 \\
B3-PW91 & HGGA & 9.1 & -9.1 & 13.9 & -13.9 & 12.5 & -12.5 \\
BH\&HLYP & HGGA & 23.8 & 23.8 & 14.6 & 14.6 & 13.4 & 13.4 \\
TPSSh & HGGA & 11.1 & -11.1 & 16.8 & -16.8 & 18.0 & -18.0 \\
PBE0 & HGGA & 8.6 & -8.6 & 20.9 & -20.9 & 25.6 & -25.6 \\
B3-P86 & HGGA & 9.8 & -9.8 & 23.1 & -23.1 & 28.4 & -28.4 \\
$\omega B 97$ & RSHGGA & 10.9 & 10.9 & 3.2 & -0.7 & 5.3 & -5.2 \\
$\omega B 97-X$ & RSHGGA & 8.1 & 8.1 & 4.3 & -3.4 & 8.5 & -8.5 \\
PW6-B95 & HMGGA & 4.5 & -4.1 & 5.9 & -3.5 & 5.7 & 0.6 \\
M06 & HMGGA & 5.3 & -5.1 & 7.4 & -5.0 & 7.2 & -3.3 \\
B1-B95 & HMGGA & 7.8 & -7.8 & 6.4 & -3.2 & 7.4 & 5.4 \\
BMK & HMGGA & 5.0 & 3.9 & 5.7 & 5.2 & 7.7 & 7.7 \\
M06-2X & HMGGA & 5.3 & 2.7 & 11.5 & -11.5 & 18.7 & -18.7 \\
$\tau-$-HCTHh & HMGGA & 10.0 & -10.0 & 19.1 & -19.1 & 23.0 & -23.0 \\
M06-HF & HMGGA & 10.6 & 9.2 & 19.9 & -19.9 & 31.9 & -31.9 \\
ROB2-PLYP & DH & 3.2 & 3.2 & 2.9 & -1.4 & 3.4 & -2.4 \\
B2K-PLYP & DH & 3.9 & 3.9 & 2.7 & -1.6 & 3.4 & -3.0 \\
B2GP-PLYP & DH & 2.0 & 1.8 & 3.5 & -2.7 & 4.2 & -3.9 \\
DSD-BLYP & DH & 1.7 & 0.4 & 3.7 & -3.3 & 4.3 & -4.2 \\
B2T-PLYP & DH & 1.8 & 1.3 & 3.8 & -2.8 & 4.2 & -3.9 \\
B2-PLYP & DH & 2.7 & -2.0 & 5.2 & -4.9 & 5.7 & -5.6
\end{tabular}

${ }^{a}$ The standard DFT calculations were carried out in conjunction with the A'PC3 basis set, while the double-hybrid DFT calculations, which exhibit slower basis set convergence, were carried out in conjunction with the A'PC4 basis set.

${ }^{b} \mathrm{GGA}=$ generalized gradient approximation, $\mathrm{HGGA}=$ hybrid-GGA, MGGA = meta-GGA, RSHGGA = range-separated HGGA, HMGGA = hybrid-meta-GGA, DH = double hybrid.

${ }^{c}$ Reference values from W2.2.

${ }^{d}$ Reference values from W1. 
Table 4. Statistical Analysis for the Performance of DFT Procedures for the Calculation of the Barrier Heights in the WCPT Database, With and Without the Empirical D3 Dispersion Corrections ( $\triangle \mathrm{MAD}$, in $\left.\mathrm{kJ} \mathrm{mol}^{-1}\right)^{a, b}$

\begin{tabular}{llccc} 
& & \multicolumn{3}{c}{ Catalyst } \\
Functional & Type & Uncat. & $1 \mathrm{H}_{2} \mathrm{O}$ & $2 \mathrm{H}_{2} \mathrm{O}$ \\
B-LYP & GGA & -0.5 & 8.5 & 20.5 \\
PBE & GGA & -0.3 & 3.9 & 9.7 \\
TPSS & MGGA & -0.4 & 5.6 & 13.9 \\
B3-LYP & HGGA & 0.1 & 6.1 & 15.6 \\
PBE0 & HGGA & -0.3 & 4.1 & 9.7 \\
TPSSh & HGGA & -0.4 & 5.5 & 13.2 \\
BMK & HMGGA & 0.3 & 0.0 & 1.0 \\
B2-PLYP & DH & -1.9 & 2.8 & 8.2 \\
B2GP-PLYP & DH & -0.5 & 0.2 & 4.0 \\
\multicolumn{4}{l}{} \\
${ }^{a}$ Footnotes $a, b, c$, and $d$ to Table 3 apply. \\
${ }^{b}$ The tabulated values are changes in MAD: $\Delta \mathrm{MAD}=$ \\
MAD(DFT-D3) - MAD(DFT). \\
\multicolumn{5}{l}{} \\
\hline
\end{tabular}


Table 5. Statistical Analysis for the Performance of DFT Procedures in Conjunction With Smaller Basis Sets for the Calculation of the Barrier Heights in the WCPT Database ( $\triangle \mathrm{MAD}$, in $\left.\mathrm{kJ} \mathrm{mol}^{-1}\right)^{a, b}$

\begin{tabular}{|c|c|c|c|c|c|c|c|c|c|c|c|c|c|c|c|c|}
\hline \multirow[b]{2}{*}{ Functional } & \multirow[b]{2}{*}{ Type } & \multicolumn{3}{|c|}{ 6-31+G(d,p) } & \multicolumn{3}{|c|}{ 6-31+G(2df,p) } & \multicolumn{3}{|c|}{ 6-311+G(3df,2p) } & \multicolumn{3}{|c|}{$\mathbf{A}^{\prime} \mathbf{V D Z}$} & \multicolumn{3}{|c|}{$\mathbf{A}^{\prime} \mathbf{V T Z}$} \\
\hline & & Uncat. & $1 \mathrm{H}_{2} \mathrm{O}$ & $2 \mathrm{H}_{2} \mathrm{O}$ & Uncat. & $1 \mathrm{H}_{2} \mathrm{O}$ & $2 \mathrm{H}_{2} \mathrm{O}$ & Uncat. & $1 \mathrm{H}_{2} \mathrm{O}$ & $2 \mathrm{H}_{2} \mathrm{O}$ & Uncat. & $1 \mathrm{H}_{2} \mathrm{O}$ & $2 \mathrm{H}_{2} \mathrm{O}$ & Uncat. & $1 \mathrm{H}_{2} \mathrm{O}$ & $2 \mathrm{H}_{2} \mathrm{O}$ \\
\hline НCTH407 & GGA & -3.1 & 2.4 & 8.9 & -0.6 & 0.1 & -0.3 & -1.1 & 0.2 & -0.5 & 1.6 & 1.8 & 0.0 & 0.4 & 0.1 & -0.1 \\
\hline B-LYP & GGA & 0.6 & 9.6 & 21.1 & 1.6 & 5.1 & 8.7 & -0.2 & 1.2 & 3.3 & 3.8 & 8.8 & 11.5 & 0.4 & 1.4 & 2.3 \\
\hline M06-L & MGGA & -0.5 & 4.2 & 10.2 & 1.5 & 1.7 & 1.2 & 0.5 & 0.4 & 0.0 & 3.0 & 2.5 & 1.1 & 1.0 & 1.9 & 1.8 \\
\hline B97-2 & HGGA & -1.2 & 4.3 & 12.5 & 0.0 & 0.8 & 0.7 & -0.2 & 0.2 & -0.2 & 1.4 & 3.0 & 1.1 & 0.2 & 0.1 & -0.3 \\
\hline B3-LYP & HGGA & -0.2 & 7.7 & 19.7 & 0.4 & 3.2 & 7.1 & 0.1 & 0.6 & 2.8 & 1.4 & 6.7 & 9.2 & 0.0 & 0.7 & 2.1 \\
\hline X3-LYP & HGGA & 0.0 & 8.5 & 20.0 & 0.2 & 4.0 & 7.3 & 0.1 & 1.0 & 3.1 & 1.0 & 7.5 & 9.5 & -0.1 & 1.4 & 2.3 \\
\hline B3-PW91 & HGGA & -1.8 & 7.2 & 18.9 & -0.1 & 3.0 & 6.3 & -0.6 & 1.0 & 3.0 & 2.5 & 6.3 & 8.0 & 0.4 & 1.4 & 2.3 \\
\hline B97-1 & HGGA & -1.2 & 6.9 & 18.1 & 0.1 & 2.8 & 5.8 & -0.3 & 0.5 & 2.2 & 2.2 & 5.9 & 7.1 & 0.3 & 1.4 & 2.2 \\
\hline TPSSh & HGGA & -2.0 & 8.0 & 20.6 & 0.0 & 3.5 & 7.3 & -0.4 & 1.6 & 4.1 & 2.7 & 6.7 & 8.9 & 0.5 & 1.5 & 2.5 \\
\hline PBE0 & HGGA & -2.4 & 6.4 & 18.3 & -0.6 & 2.6 & 5.9 & -0.9 & 0.8 & 2.8 & 2.1 & 5.7 & 7.2 & 0.4 & 1.4 & 2.2 \\
\hline B3-P86 & HGGA & -1.6 & 7.5 & 19.0 & 0.2 & 3.1 & 6.2 & -0.5 & 0.8 & 2.8 & 2.7 & 6.4 & 8.0 & 0.4 & 1.4 & 2.3 \\
\hline$\omega \mathrm{B} 97$ & RSHGGA & 2.5 & 5.1 & 17.6 & -0.5 & 1.9 & 5.5 & 0.6 & 0.3 & 2.2 & -3.1 & 3.6 & 6.5 & -0.7 & 0.5 & 3.1 \\
\hline$\omega B 97-X$ & RSHGGA & 2.3 & 7.0 & 18.6 & -0.3 & 2.6 & 6.2 & 0.6 & 0.4 & 2.7 & -3.0 & 5.6 & 7.5 & -0.7 & 1.2 & 3.0 \\
\hline M06 & HMGGA & 0.1 & 5.8 & 14.6 & 1.8 & 2.0 & 3.2 & 0.5 & 0.4 & 1.9 & 3.9 & 5.3 & 5.5 & 1.1 & 1.6 & 2.4 \\
\hline B1-B95 & HMGGA & -1.6 & 3.6 & 6.4 & -0.1 & 0.8 & -2.2 & -0.7 & 0.2 & -1.4 & 2.6 & 3.3 & -1.8 & 0.7 & 0.2 & -1.2 \\
\hline BMK & HMGGA & 2.1 & -1.0 & 0.6 & 0.1 & -0.2 & -2.0 & 0.7 & -0.2 & -1.5 & -0.7 & -0.7 & -2.0 & -0.6 & -1.3 & -3.4 \\
\hline M06-2X & HMGGA & 0.8 & 9.6 & 22.6 & -0.1 & 4.2 & 7.5 & 0.0 & 2.0 & 5.2 & 0.3 & 7.4 & 8.6 & -0.5 & 2.3 & 3.8 \\
\hline$\tau$-HCTHh & HMGGA & -1.2 & 8.9 & 21.2 & 0.6 & 4.1 & 7.8 & -0.2 & 1.8 & 4.3 & 3.2 & 7.5 & 9.7 & 0.5 & 1.5 & 2.5 \\
\hline M06-HF & HMGGA & 1.3 & 15.6 & 35.2 & -0.5 & 7.7 & 15.4 & -0.4 & 7.0 & 13.1 & -0.7 & 13.0 & 18.9 & -0.3 & 5.4 & 8.8 \\
\hline ROB2-PLYP & $\mathrm{DH}$ & 5.9 & 1.7 & 12.1 & 1.7 & 0.5 & 2.2 & 1.7 & -0.1 & 1.3 & -0.8 & 2.0 & 3.8 & -0.1 & 0.6 & 1.8 \\
\hline B2K-PLYP & $\mathrm{DH}$ & 8.0 & 1.1 & 9.6 & 2.7 & 0.5 & 1.4 & 2.2 & -0.4 & 1.2 & 0.2 & 1.0 & 2.6 & 0.1 & 0.6 & 2.4 \\
\hline B2GP-PLYP & $\mathrm{DH}$ & 6.9 & 1.1 & 11.1 & 2.1 & 0.0 & 1.8 & 1.9 & -0.3 & 1.5 & -0.1 & 1.8 & 3.5 & 0.0 & 0.7 & 2.4 \\
\hline DSD-BLYP & $\mathrm{DH}$ & 6.8 & 0.5 & 9.7 & 1.6 & -0.3 & 1.3 & 1.0 & -0.5 & 1.4 & -0.3 & 1.6 & 3.0 & -0.1 & 1.0 & 2.7 \\
\hline B2T-PLYP & $\mathrm{DH}$ & 5.7 & 1.5 & 12.1 & 1.4 & 0.2 & 2.4 & 1.3 & -0.2 & 1.6 & -0.4 & 2.3 & 4.1 & -0.1 & 0.7 & 2.3 \\
\hline B2-PLYP & $\mathrm{DH}$ & 1.6 & 2.2 & 13.4 & -0.3 & 0.5 & 3.3 & -0.7 & -0.1 & 2.0 & 0.5 & 3.5 & 5.2 & 0.0 & 1.1 & 2.6 \\
\hline
\end{tabular}

${ }^{a}$ Footnotes $a, b, c$, and $d$ to Table 3 apply.

${ }^{b} \triangle \mathrm{MAD}=\mathrm{MAD}(\mathrm{DFT} /$ specified basis set $)-\mathrm{MAD}(\mathrm{DFT} /$ large basis set $)$, where MAD(DFT/large basis set $)$ are given in Table 3. 
Table 6. Statistical Analysis for the Performance of Theoretical Procedures for the Calculation of the Tautomerization Energies in the WCPT Database (Relative to W2.2 Reference Reaction Energies, in $\left.\mathrm{kJ} \mathrm{mol}^{-1}\right)^{a}$

$\begin{array}{lcc}\text { Procedure } & \text { MAD } & \text { MD } \\ \text { MP2 } & 2.8 & 2.4 \\ \text { SCS-MP2 } & 3.0 & 1.4 \\ \text { MP4 } & 3.2 & 2.3 \\ \text { G4(MP2)-6X } & 2.1 & 1.8 \\ \text { G4(MP2) } & 1.3 & 0.3 \\ \text { G4 } & 1.8 & 1.8 \\ & & \\ \text { HCTH407 } & 5.7 & 0.6 \\ \text { B-LYP } & 4.2 & -0.3 \\ \text { B97-D } & 4.4 & 0.0 \\ \text { PBE } & 4.3 & 0.0 \\ \text { M06-L } & 7.5 & 3.0 \\ \tau \text {-HCTH } & 4.4 & 0.5 \\ \text { TPSS } & 4.4 & 0.8 \\ \text { B97-2 } & 4.2 & 0.8 \\ \text { B3-LYP } & 4.0 & 0.1 \\ \text { X3-LYP } & 3.9 & 0.1 \\ \text { B97-1 } & 3.9 & 1.3 \\ \text { B3-PW91 } & 4.2 & 0.5 \\ \text { BH\&HLYP } & 3.8 & 0.7 \\ \text { TPSSh } & 4.3 & 1.0 \\ \text { PBE0 } & 4.0 & 0.6 \\ \text { B3-P86 } & 4.1 & 0.4 \\ \omega B 97 & 6.2 & 0.8 \\ \omega B 97-X & 4.1 & 0.6 \\ \text { PW6-B95 } & 3.5 & 0.1 \\ \text { M06 } & 4.7 & 2.5 \\ \text { B1-B95 } & 3.5 & 0.2 \\ \text { BMK } & 5.9 & 5.0 \\ \text { M06-2X } & 3.6 & -1.4 \\ \tau \text {-HCTHh } & 4.2 & 1.2 \\ \text { M06-HF } & 11.3 & -3.9 \\ \text { ROB2-PLYP } & 3.2 & 1.5 \\ \text { B2K-PLYP } & 3.0 & 1.8 \\ \text { B2GP-PLYP } & 3.1 & 1.7 \\ \text { DSD-BLYP } & 2.9 & 1.8 \\ \text { B2T-PLYP } & 3.2 & 1.6 \\ \text { B2-PLYP } & & \\ \text { calculations were carried out in } & \\ \text { conjunction with the A'VQZ, A'PC3, and } \\ \text { A'PC4 basis sets, respectively. } & \\ & & \\ & & \\ & & \end{array}$


TOC Graphic

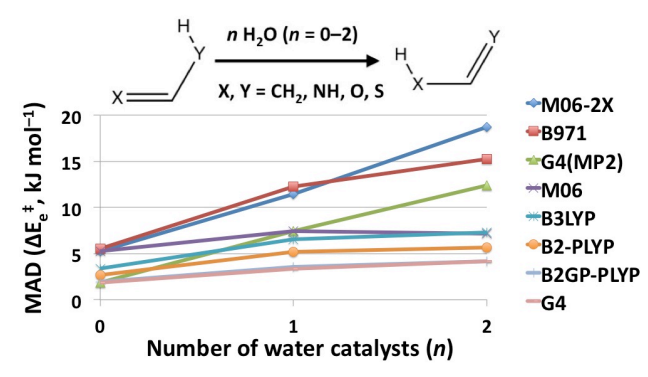

